\title{
ETHICS IN DESIGN EDUCATION, BUT DIFFERENT; PRACTICING THE PRACTICAL TURN
}

\author{
Wouter EGGINK \\ University of Twente
}

\begin{abstract}
Design education has looked for different approaches to teaching ethics and ethical behaviour. In this paper I want to add an approach that is coming from the collaboration between design research and philosophy of technology. Philosophy of Technology has produced a substantive number of theories and reflections about the impacts of technology and innovations on our daily lives and social behaviours. To make the reflections from philosophy of technology more tangible for design engineering students we experimented over the years with different tools and practical approaches in order to integrate these perspectives directly in the design process. In analogy with the empirical turn before, we named this closer integration with design 'the Practical Turn in Philosophy of Technology'. My argument now is that by using these insights, one can cultivate ethical reflection with design engineering students by directly informing their design process in what I call 'practicing the practical turn'.

In this paper I will show this approach alongside the results of a one week workshop with a group of students from the University of Antwerp in the context of responsible design for public space.
\end{abstract}

Keywords: Ethical reflection, practical turn, philosophy of technology, social design, responsible design

\section{INTRODUCTION}

Industrial Design Engineers have social responsibility by the very nature of their activities; bringing new products and services into the world of the user [1]. This responsibility calls for ethical awareness in the education of future design engineers, as they will be influencing the impacts of technology on people and society for better or worse. In our curriculum at the University of Twente we approach this responsibility from the perspective of human-technology relations on three different levels [2]. The first level is the individual relation between a user and product, where we want to emphasize that good design starts with understanding and designing the intended relation, before shaping the actual technology. At the second level we look at how products can influence and shape relations between people; the social level. The highest level is the societal level; where design can address issues like sustainability, healthiness, and inclusivity. In order to show how responsibility and responsible behaviour in this context should be understood we developed the framework of Responsible Design $[3,4]$ where three different strands provide for practical tools and theories in; (1) designers acting responsibly, (2) enabling others in society to act responsibly, and (3) producing things that do not destroy the world. The first strand is mainly informed by human centred design. The second and third strand are in our context heavily informed by philosophy of technology.

\section{DESIGN, ETHICS, AND PHILOSOPHY OF TECHNOLOGY}

Philosophy of technology has produced a substantive number of theories and reflections about the impacts of technology and innovations on our daily lives and social behaviours. Collaboration between design research and philosophy of technology for responsible design is therefore very promising. The reflective, philosophical perspective brings the societal implications of design to the fore. Since the philosophy of technology in the current of the 'empirical turn' aims to study concrete technologies and contexts, contributions from philosophy to design have become all the more feasible. Design research can use the frameworks of philosophers to theorize the findings from practice, to make sense of the past, and for ethical reflection on the impacts of design and the moral responsibilities of designers. Or, still more practical, philosophical insights in the relationships between humans and technology can contribute to design for usability and design for behaviour change [5]. On the other hand, the practice 
of designing actual things provides a laboratory for putting philosophical frameworks to the test and to use in the real world [6]. A clear example of the use of philosophy of technology in the development of ethical awareness is the concept of ethics in technology by Verbeek [7]. Moreover, Verbeek coined the idea of "technology design as experimental ethics" [5] and argues that by carefully assessing, anticipating, and eventually shaping the influences of technology, designers can take responsibility for the inevitable changes (for better or worse) they will bring to the lives of individual users, the dynamics of social groups, and society at large.

One can critique however with Sonneveld that "ethical reflection in design, considering values such as wellbeing, safety, autonomy, responsibility, and so on, is often a theoretical perspective: focussed on abstract users and abstract use situations [...] Although illustrated with concrete examples, the theory remains theoretical, searching for a general position a designer should develop towards users." [8] One way to overcome this is to focus on the development of the designer as a person and promoting the awareness of both professional and personal values $[9,10]$. I recognise this is highly valuable, however also want to advocate a complementary approach here.

To make the reflections from philosophy of technology more tangible for design engineering students we experimented over the years with different tools and practical approaches [11-13] in order to integrate these perspectives directly in the design process. In analogy with the empirical turn before, we named this closer integration with design 'the Practical Turn in Philosophy of Technology' [14]. My argument now is that by using these insights, one can cultivate ethical reflection with design engineering students by directly informing their design process in what we call 'practicing the practical turn' [15].

\section{PRACTICING THE PRACTICAL TURN}

In this paper I will explore this approach, based on the experiences with a one-week Industrial Design Workshop at the University of Antwerp. Here, 17 second and third year bachelor students executed a conceptual design project for the improvement of public space. During the process they experienced and applied tools and theories we developed in the context of the Practical Turn. A total of three different tools an theories were explored, respectively Utopian Technology [16], the Product Impact Tool [17], and Open Script Design [18]. Within a total of five design projects the results ranged from an open electric bike-sharing system to a bus-stop that fosters ethical discussion.

\section{WORKSHOP WEEK 'RESPONSIBLE DESIGN'}

The actual workshop was based on the concept of responsible design. The word "responsibility" contains the verb "to respond". One can therefore interpret responsible design quite literally by responding to the needs of society. The workshop was meant to explore this by researching the concept of Open Script design, as developed by Stam [19]. Open script design means that some designs are more open for interpretation by the user than others. Think of LEGO bricks versus a Barbie Doll. In theory, an open script will also delegate the responsibility from the designer to the user and therefore enable them to 'act responsibly' [4].

\subsection{Set up of the workshop}

\begin{tabular}{|c|c|c|c|c|}
\hline $\begin{array}{l}-- \\
\text { Introduction } \\
+ \\
\text { "Valuable Object" }\end{array}$ & $\begin{array}{l}\text { Modernism/Post- } \\
\text { Modernism } \\
+ \\
\text { Utopian Design }\end{array}$ & $\begin{array}{l}\text { Mediation Theory } \\
+ \\
\text { Finding } \\
\text { Product/situation/ } \\
\text { service to redesign } \\
+ \\
\text { Documenting/PIT }\end{array}$ & Concept design & $\begin{array}{l}\text { Preparation of } \\
\text { Exhibit } \\
\text { Feedback on } \\
\text { Results }\end{array}$ \\
\hline $\begin{array}{l}\text { Setting up first } \\
\text { part of Exhibition }\end{array}$ & $\begin{array}{l}\text { Finding Utopian } \\
\text { Design Examples } \\
+ \\
\text { Setting up second } \\
\text { part of Exhibition }\end{array}$ & $\begin{array}{l}\text { "Opening-up the } \\
\text { script" }\end{array}$ & Prototyping & $\begin{array}{l}\text { Setting up final } \\
\text { part of Exhibition } \\
\text { Exhibition and } \\
\text { Drinks }\end{array}$ \\
\hline
\end{tabular}

Figure 1. Set-up of the one-week (Monday-Friday) workshop with morning (top) and afternoon (bottom) sessions 
Figure 1 shows the full program of the workshop. It started Monday morning with a sort of warming up round around the question of value of products and ended with the presentation of the workshop results in a physical exhibition at Friday afternoon. The students had to bring (a picture of) an object that was valuable to them and then explain each other why this was the case. The students then set up the first part of the exhibition, showing the results of their discussions. Adhering to the central theme of "responsibility", the students had to find out themselves (and negotiate together) how to do this best. In the meantime, the participating students were divided in 5 groups according to their own liking. These groups stayed together throughout the rest of the week. On the second day we looked into the concept of Utopian Design and on Wednesday the groups had to formulate themselves a design challenge in the form of a specific public space (problem or challenge) to redesign.

\subsection{Results of the workshop}

Utopian Technology is a philosophy of technology perspective on design by Dorrestijn [20], based on the notion that in design history, several periods and accompanying movements are distinguishable that envisioned to radically change society through design. In the approach he uses Arts \& Crafts, Modernism, Late modernism, and Postmodernism as possible guiding principles. These four periods then respectively lead to a 'restorative', a 'socially-functionalistic', a 'technology-at-a-human-scale', and a 'diversity-of-lifestyles' utopian vision on design. After a thorough explanation of these concepts, the students were sent out to find examples of designs and situations that could reflect these different visions in public space. Figure 2 shows some examples of images that the students presented after this exercise. The café-table with raw planks is a typical example of a restorative utopia where the connection with nature stands for honesty in material use and craftsmanship, resulting in what is supposed to be an improved experience of 'being human'. The public bike sharing system on the right is a fine example of the socially-functionalistic perspective on society; all the bikes are the same and the user has to obey to the system (taking out and putting back the bike in a pre-defined place) to make it work. The electric scooters in the middle are part of a sharing system without docking stations. The latter is improving the user experience on an individual human scale, however the students also recognised that the individual behaviour of users was a cause of collective nuisance, because of discarded or abandoned scooters scattering around the streets. This led the student group to rethink and redesign the system in the second part of the workshop.
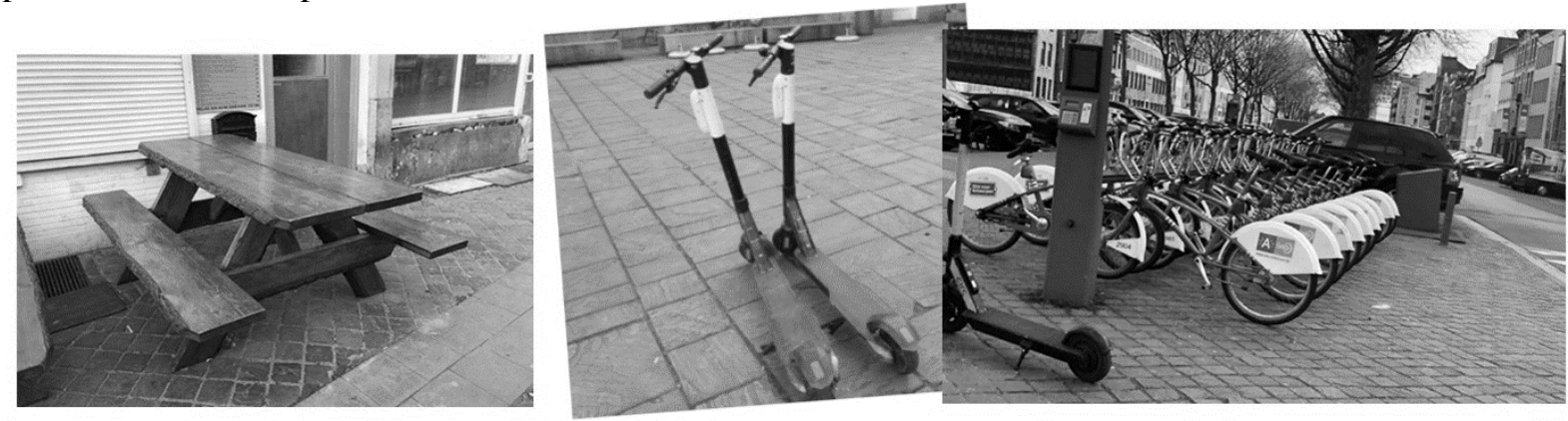

Figure 2. Examples of Utopian Design that were collected outside the classroom by the students: restorative, technology-at-human-scale, and socially-functionalistic

"Opening up the script" means that you can reconsider products, designs, or situations to be more open to the preferences of the user. This openness can both be applied to the functionality as well as to the meaning of an artefact. A picnic blanket can for instance also be used as a cover for protection against the rain. The same blanket can also be both protective ("this is my spot") as well as inviting ("come sit over here"). Openness can also mean that there is room for a contribution of the user, for instance when you are decorating the picnic blanket yourself.

In the exercise the students were asked to think of aspects that were related to their design challenge and find out how they could be more 'open' or 'closed'. Figure 3 shows an example of opening up the script of an amphitheatre by the student group that set themselves to redesign public playgrounds. The openness of the script in the redesign was about functionality; the amphitheatre could also be used as stepping stones or obstacle course. Interestingly, the redesign also showed a counteracting effect as the audience in the traditional amphitheatre setting would have more possibilities to sit together. 


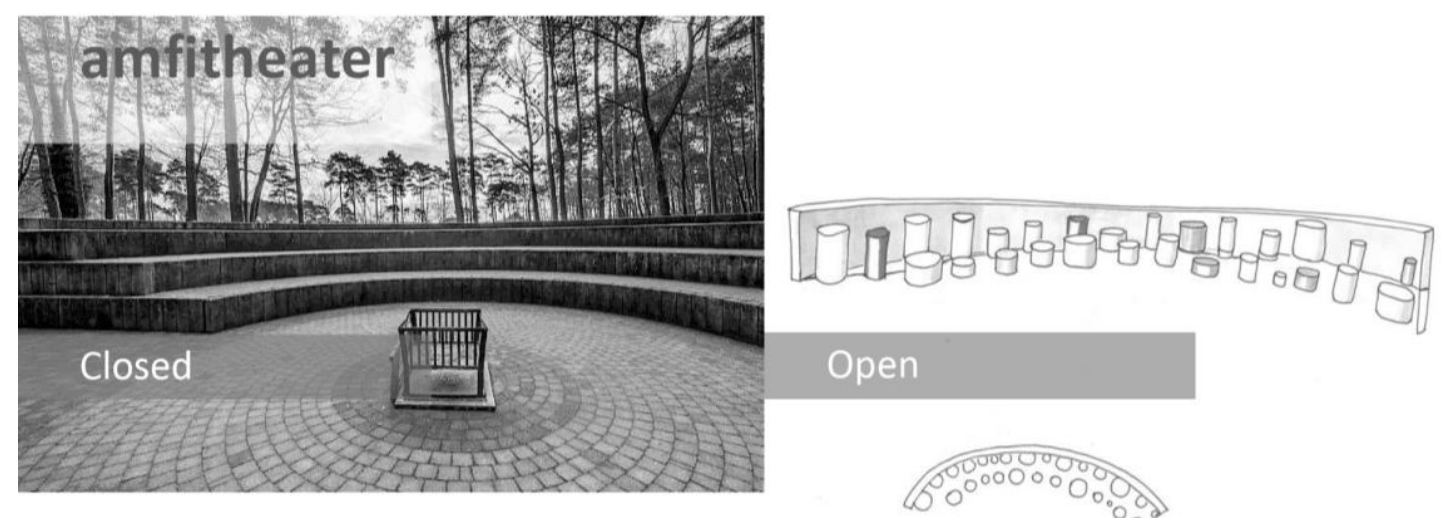

Figure 3. Example of open-script and closed-script comparison and ideation of a student group (by Janne Caenen, Lotte Van Hoofstat \& Salma Yachchou)

The Product Impact Tool is a framework, derived from Philosophy of Technology and User Centred design that addresses the multitude of impact types that technologies have on humans and human behaviour [17]. It offers a repertoire of exemplary types of impact, presented as different sides or different levels of affection. The impacts, or influences are categorized in four quadrants, named beforethe-eye, to-the-hand, behind-the-back, and above-the-head. The student groups had to use the worksheet to analyse their design challenge and ideate problems and solutions within all the four quadrants (figure 4). The interesting thing is that the tool forces to also think of the less obvious and sometimes hidden effects of technology. By making several 'rounds' through the four quadrants, these often unwanted side effects come to the fore [12]. The positive side-effect of the exercise itself is that it naturally becomes apparent that solutions can also come from all four quadrants.

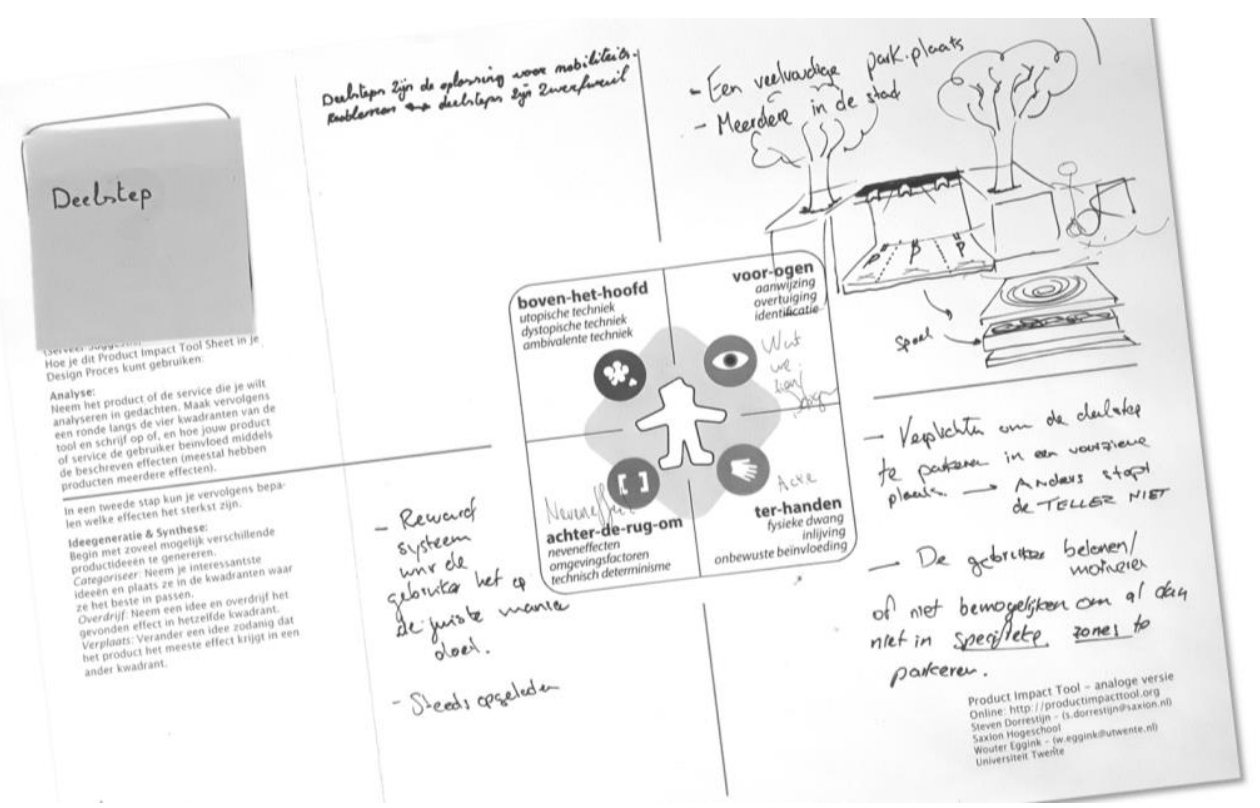

Figure 4. Example of Product Impact Tool analysis and ideation (steps project) of a student group (by Kobe Baudewijns, Emile Cognie, Pieter De Beucker \& 1 other student)

After the documentation phase and the analysis and ideation with the product impact tool, the students had to develop their concepts and present them at the end of the day. Some examples of the ideas presented by the student group working at the electric scooter system are shown in figure 5. One might say that due to the priming exercises with utopian design and opening up the script, the presented solutions differed heavily. The first solution, depicted on the right is based on the principle that the scooter system itself will not allow to discard them in an unwanted place (the red areas). This can be seen as a correction on the technology-at-a-human-scale solution, where the responsible behaviour is build-in in the technology itself. The students recognised that this is then actually also a movement in the direction of the socially-functionalistic utopia because the user has to obey to the system. Also, problems may arise when the system is not absolutely clear in communicating the 'forbidden' areas. 

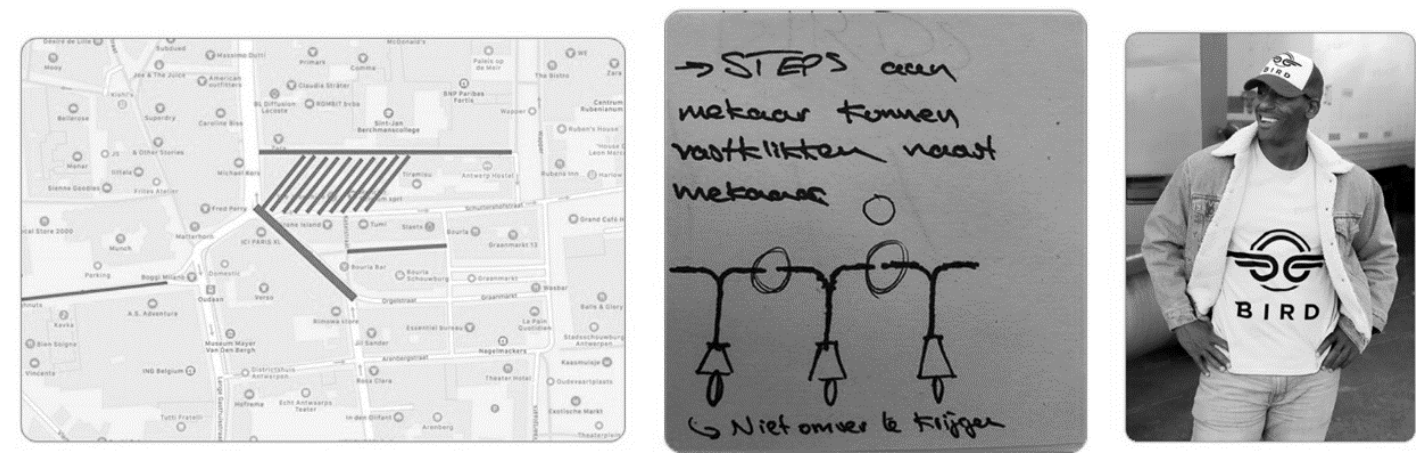

Figure 5. Visuals of ideation for solutions on the problem of nuisance by an electric step sharing system (by Kobe Baudewijns, Emile Cognie, Pieter De Beucker \& 1 other student)

The second solution, sketched in the middle was geared towards cooperation. The scooters could only be discarded by connecting them to another scooter, thus resulting naturally in the sociallyfunctionalistic ideal of 'neat' rows of scooters. This would also prevent them from falling over, which was unwantedly associating them with rubbish. The last solution depicted here was based on stimulating preferable behaviour by incentives. The 'good' user would be rewarded with specific merchandise. This is very much related to the diversity-of-lifestyles utopia, where the user remains totally free to choose their behaviour. The idea was also that the users behaving properly would become natural ambassadors for the scooter system. This led eventually to a new discussion whether this was desirable. By being connected to the brand, the ambassadors could also become held accountable for the misuse of others. This paper leaves no room to show all the results of the five student groups and the associated exhibition, however I hope that I have shown how the different philosophy of technology inspired exercises stimulated the ethical reflection among the students in a natural and practical way. This by showing them the dilemmas connected to design, coming directly from their own results in practice.

\section{DISCUSSION}

Apart from having interesting design results, the project shows how design can make tangible the inherent dilemmas and conflicts in designing for public space, where collective responsibilities and individual concerns often collide. Supported by the exercises and presented theories, this led to both a high amount and a high level of ethical discussions during the week. In my opinion it did not so much lead to better designs in the sense that they would be readily applicable, however the students were in the end very profound in explaining the dilemmas around their designs and in defending their decisions. In interpreting the positive results of the different tools, one should however take into account a possible bias in the group of students as they all applied voluntarily for a workshop about responsible design. So, one might expect that they were also more than averagely interested in ethics in design. However, there was no mentioning ethics in the first place. It is that with the practicing of responsible design, the ethical discussions come naturally to the fore.

In the end, the experiences were more interesting than the results, although the experiences could not have been so interesting without the intermediate design results. This is what we call the reciprocal effect of the combination of design with philosophy of technology [15]. The conceptual designs are informed by the reflective analyses of the philosophical tools, while in turn, the ethical reflections are informed by the practical examples of the concrete design proposals.

\section{CONCLUSIONS}

The experiences -even more than the results- during the one-week workshop make a case for the Practical Turn, that shows an inherent reciprocal effect. Through the materialization and visualization of ethical and social issues with design -based on the ethical reflection from the philosophical tools and theories- the ethical reflection in its turn is explicated. By practicing the practical turn, students can experiment with and 'feel' the ethical dilemmas and conflicts of their future profession in a way that is very closely related to their design practice.

\section{ACKNOWLEDGEMENTS}

The author likes to thank all student participants in the workshop and the University of Antwerp for their generous hospitality. 


\section{REFERENCES}

[1] Papanek V. The Green Imperative. 1995, London: Thames and Hudson.

[2] Eggink W. Where's My Robot? Integrating Human Technology Relations in the Design Curriculum. In: Proceedings of the 16th International Conference on Engineering and Product Design Education (E\&PDE). 2014. Enschede (the Netherlands): The Design Society. pp. 87-92.

[3] Eggink W. Framing the Social Responsibility of the Design Engineer, In: Project proposal for the Program for Science Based Engineering - Post doctoral research grant. 2015, University of Twente: Enschede (the Netherlands). pp. 1-4.

[4] Eggink W. et al. Setting the stage for Responsible Design. In: Proceedings of the biannual Design Research Society conference (DRS) Synergy. 2020. Brisbane (Australia): Design Research Society. pp. 713-730.

[5] Verbeek P. P. Technology Design as Experimental Ethics, In: Ethics on the Laboratory Floor, S. van den Burg and T. Swierstra (Eds.). 2013, Palgrave Macmillan: Basingstoke. pp. 83-100.

[6] Eggink W. and Dorrestijn S. Editorial: Philosophical Tools in Design Research: from empirical turn to practical turn. In: Proceedings of the biannual Design Research Society conference (DRS) Catalyst. 2018. Limerick (Ireland): Design Research Society. pp. 188-189.

[7] Verbeek P. P. Materializing Morality: Design Ethics and Technological Mediation. Science, Technology \& Human Values, 2006. 31(3): pp. 361-380.

[8] Sonneveld M. Positive Ethics in Design Education. In: Proceedings of the 16th International Conference on Engineering and Product Design Education (E\&PDE). 2014. Enschede (the Netherlands): The Design Society. pp. 87-92.

[9] Hiort af Ornäs V. and Keitsch M. Ethics in Design Curricula - Teaching Approaches. In: Proceedings of the 18th International Conference on Engineering and Product Design Education (E\&PDE). 2016. Aalborg (Denmark): The Design Society.

[10] Ledsome C. Learning to be a Professional Designer. In: Proceedings of the 21th International Conference on Engineering and Product Design Education (E\&PDE). 2019. University of Strathclyde, Glasgow: The Design Society. pp. 1-6.

[11] Belle J. V., Dijk J. V. and Eggink W. Towards a Tangible Philosophy through Design; Exploring the question of being-in-the-world in the digital age. In: Proceedings of the Academy for Design Innovation Management conference (ADIM). 2019. London: Academy for Design Innovation Management.

[12] Belle J. V., Dorrestijn S. and Eggink W. Design for People \& Society: Turning the Product Impact Tool into a Design Tool. In: Proceedings of the Philosophy of Human Technology Relations Conference (pHTR). 2018. DesignLab, Enschede (the Netherlands): University of Twente.

[13] Belle J. V., Giesberts B. and Eggink W. The Use of Philosophical Theories in Design: A ResearchThrough-Design Case of Treatment Compliance. In: Proceedings of the biannual Design Research Society conference (DRS). 2018. Limerick (Ireland): Design Research Society. pp. 218-228.

[14] Eggink W. and Dorrestijn S. Philosophy of Technology x Design: The Practical Turn. In: Proceedings of the biannual Design Research Society conference (DRS). 2018. Limerick (Ireland): Design Research Society. pp. 190-199.

[15] Eggink W. and Dorrestijn S. Responsible Design by Philosophical Tools in Parallel Trajectory: Practicing the Practical Turn. In: Proceedings of the 2nd Philosophy of Human Technology Relations Conference (pHTR). 2020. Online Conference, Enschede: University of Twente.

[16] Dorrestijn S. and Verbeek P. P. Technology, Wellbeing, and Freedom: The Legacy of Utopian Design. International Journal of Design, 2013. 7(3): pp. 45-56.

[17] Dorrestijn S. and Eggink W. Product Impact Tool Workshop; mastering affect and effect in humanproduct relations. In: Proceedings of the International Conference on Design \& Emotion; Colors of Care. 2014. Bogotá: Ediciones Uniandes. pp. 467-469.

[18] Stam L. and Eggink W. How to Interest People for the Hare instead of the Chase, an exploration of open script design to change consumer behaviour. In: Proceedings of the biannual Design Research Society conference (DRS). 2014. Umeå: Design Research Society.

[19] Stam L. Social Engagement in Design: a new perspective. Ma in Industrial Design Engineering, 2015, University of Twente, Enschede (the Netherlands)

[20] Dorrestijn S. The design of our own lives, PhD in Philosophy of Science, Technology and Society, 2012, University of Twente, Enschede (the Netherlands). 